\title{
8
}
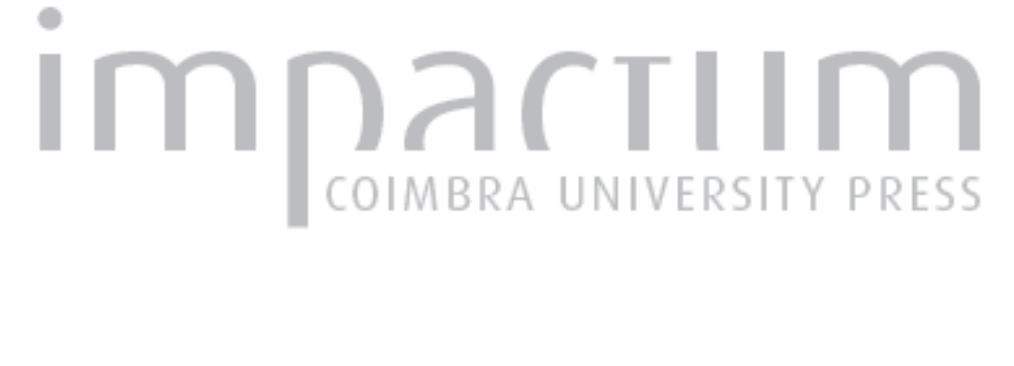

\section{Aspectos do relevo calcário em Portugal: os poljes de Minde e de Alvados}

Autor(es): Martins, Fernandes

Publicado por: Faculdade de Letras da Universidade de Coimbra

URL persistente:

URI:http://hdl.handle.net/10316.2/39269

DOI:

DOI:http://dx.doi.org/10.14195/0871-1623_1_2

Accessed : $\quad$ 26-Apr-2023 13:06:20

A navegação consulta e descarregamento dos títulos inseridos nas Bibliotecas Digitais UC Digitalis, UC Pombalina e UC Impactum, pressupõem a aceitação plena e sem reservas dos Termos e Condições de Uso destas Bibliotecas Digitais, disponíveis em https://digitalis.uc.pt/pt-pt/termos.

Conforme exposto nos referidos Termos e Condições de Uso, o descarregamento de títulos de acesso restrito requer uma licença válida de autorização devendo o utilizador aceder ao(s) documento(s) a partir de um endereço de IP da instituição detentora da supramencionada licença.

Ao utilizador é apenas permitido o descarregamento para uso pessoal, pelo que o emprego do(s) título(s) descarregado(s) para outro fim, designadamente comercial, carece de autorização do respetivo autor ou editor da obra.

Na medida em que todas as obras da UC Digitalis se encontram protegidas pelo Código do Direito de Autor e Direitos Conexos e demais legislação aplicável, toda a cópia, parcial ou total, deste documento, nos casos em que é legalmente admitida, deverá conter ou fazer-se acompanhar por este aviso.

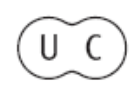




\section{INSTITUTO DE ESTUDOS GEOGRÁFICOS}

FACULDADE DE LETRAS - UNIVERSIDADE DE COIMBRA
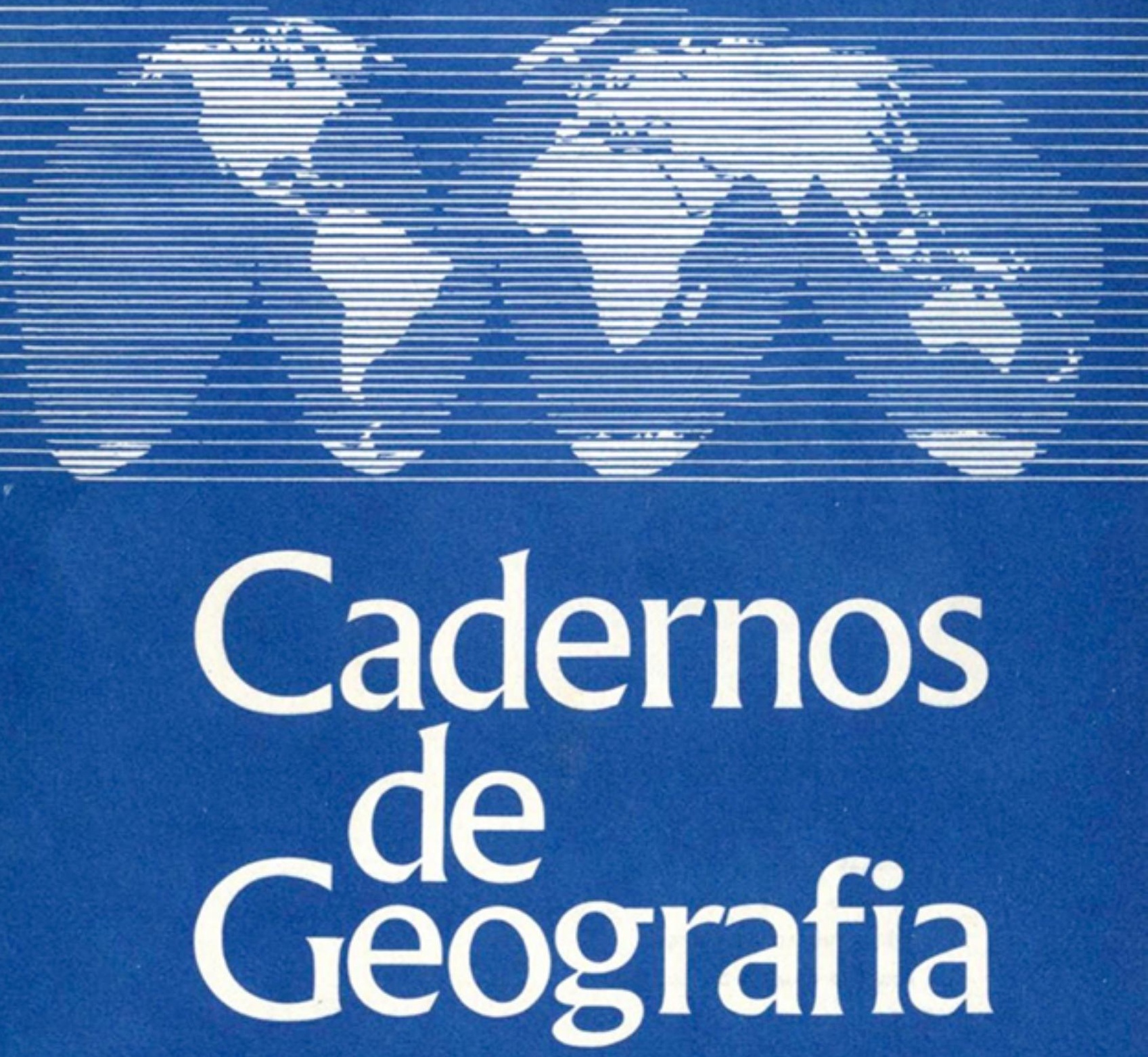

1 


\section{ASPECTOS DO RELEVO CALCÁRIO EM PORTUGAL: OS POLJES DE MINDE E DE ALVADOS}

A propósito do calcário já De Martonne anotou que «nenhuma rocha marca a sua presença na topografia de maneira mais evidente, nem imprime à paisagem um cunho tão original nem tão indelével» 1 ; e porque, efectivamente, são assim tão vincadas as influências petrográficas deste material litológico na génese e evolução das formas e, também, porque paralelamente implicam peculiares condições hidrográficas, é óbvio que nas regiões portuguesas onde aflora, logo o calcário se traduz no relevo pela singulariedade do desenvolvimento topográfico e se denuncia ainda pela penúria, senão mesmo pela carência total, da drenagem subaérea.

Ora, como em Portugal o domínio dos calcários se confina, por assim dizer, às orlas mesozóicas - porque são raros e de reduzidas dimensões os afloramentos na área do maciço antigo - , naturalmente só nas regiões que respeitam àquelas unidades geológicas se nos deparam amostras interessantes da morfologia cársica. No entanto, dado que «o calcário não é de modo algum uma entidade petrográfica» ${ }^{2}$, pois tal «etiqueta rotula materiais bem diversos» ${ }^{3}$, e ainda porque o tipo estrutural difere de uma zona para outra, assim como variam a espessura e o arranjo do complexo calcário - daí resultam diversos jogos de circunstâncias que, exactamente porque são diferentes, implicaram díspar evolução do relevo e suscitaram desigualdade nas condições hidrográficas, factos esses logo patentes quando se estabelece confronto entre aqueles vários compartimentos das orlas.

Certo é que o predomínio da rocha nua ou mal revestida por uma vegetação rala, bem como os campos de lapiez, os bastiões rochosos - penas e arrifes - , a íngreme descida de vertentes talhadas na rocha viva, a verticalidade das paredes de alguns pequenos canyons e ainda a rede dos vales secos, as formas superficiais fechadas ou com tendência para fechar-se, os

1 De Martonne, Traité de Géographie Physique, 5. ${ }^{\mathrm{a}}$ ed., Paris, 1935, tomo II, cap. VI, § 1, pág. 649 .

2.3 René Clozier, Les Causses du Quercy - Contribution à la géographie physique d'une région calcaire, Paris, 1940, pág. 58. 
algares (avens), e a drenagem subterrânea dão a todos esses compartimentos o mesmo ar de família. Todavia, e muito embora esses índices, ou apenas alguns deles, constituam o leit-motiv da topografia e sejam constantes da paisagem quer no planalto de Cantanhede, na serra da Boa-Viagem ou na de Sicó, quer em Montejunto, nos arredores de Cascais, na Arrábida ou no Algarve Calcário, os reconhecimentos efectuados e um ou outro estudo de mais pormenor permitem já discernir diferenças bem evidentes e afirmar que é no Maciço Calcário Estremenho, também chamado de Porto de Mós, que o morfologista encontra a mais bela amostra do relevo calcário português 1 .

Neste breve trabalho não me proponho estabelecer um esquema geral das diferenças que decorrem da análise das formas e das condições hidrográficas dos compartimentos acima referidos e renuncio até a esboçar, repetindo-me, a imagem morfológica global daquele Maciço; não é sequer meu intuito rectificar aqui hipóteses minhas acerca da evolução do relevo desta região estremenha, nem discutir se carecem ou não de ser confirmadas aquelas outras formuladas pelo meu amigo Doutor Pierre Birot e que são algum tanto discordantes das que tive ocasião de emitir ${ }^{2}$. Por agora é, apenas, meu propósito dar de novo uma curta notícia sobre os poljes de Minde e de Alvados (Fig. 1-a e -b), que reputo serem as duas mais belas formas cársicas portuguesas.

Esses dois poljes estão situados no Maciço Estremenho e dispõem-se ao longo de uma mesma linha de deslocação que cinde transversalmente 0 bloco calcário; porém, como esse sulco transversal é constituído por dois tramos com aparente desligamento horizontal, acontece não estarem perfeitamente alinhados, porque cada um deles se afeiçoou em seu tramo, ficando o de Alvados no mais setentrional.

Se nas linhas gerais a arquitectura de ambos os poljes é, ainda que mais complicada no de Alvados, sensivelmente a mesma, já pelo que respeita à evolução não poderá dizer-se outro tanto. Um breve escorço monográfico desses poljes apoiará estas afirmações.

1 Vide: Fernandes Martins, Maciço Calcário Estremenho-Contribuição para um estudo de geografia física, Coimbra, 1949. Na bibliografia anexa fez-se referência aos trabalhos de outros autores que interessam ao estudo da região.

2 Afigura-se-me, por exemplo, que necessitará de confirmação a hipótese de Birot que atribui idade cretácica à desmantelada cobertura detrítica siliciosa [Cf. P. BIROT, Le Portugal - Étude de géographie régionale (Collection Armand Colin, n. ${ }^{\circ} 260$ ), Paris, 1950, pág. 138 e fig. 14]. Provavelmente, essa cobertura datará do Paleógeno, e, em todo o caso, terá de ser post-cretácica visto que num dos retalhos dela pude recolher um calhau rolado de arenito do Buçaco (Vide: Fernandes Martins, Maciço Calcário Estremenho, já cit., págs. 120 e segs.). 
Polje de Minde. - Embora seja um lídimo representante deste tipo de formas, e até a mais ampla de quantas se inscrevem na área do Maciço, tem exíguas dimensões - cerca de $4 \mathrm{~km}$. de comprimento por 1800 metros de largura máxima. Está encastoado numa depressão monoclinal, suscitada esta por uma falha de forte rejeito, cuja grandiosa escarpa - a Costa de Minde -, cortada nos calcários margosos do Liássico, que formam íngreme talude, e coroada por uma cornija de calcários bajocianos, se levanta, a SW,

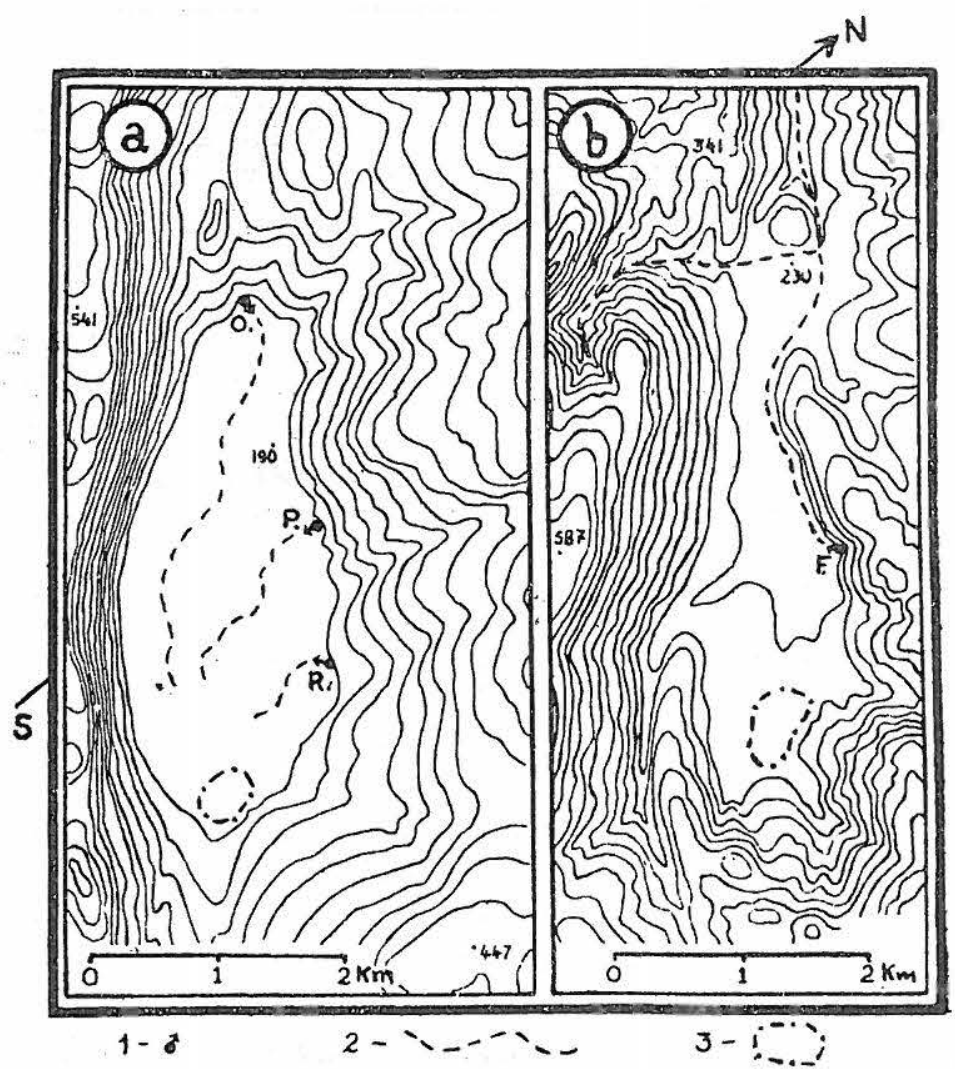

Frg. 1-Os poljes de Minde (a) e de Alvados (b). Escala: 1/75.000 aproximadamente. Equidistância: $25 \mathrm{~m}$.

1-Ponors; 2 - leito dos cursos temporários que surdem dos ponors ou de exsurgências ocasionais; 3 - depressões satélites dos poljes.

Abreviaturas: O. - Olho da Mira; P. - Poio; R. - Regatinho; F. - Falsa.

As Costas de Minde e de Alvados estão bem evidenciadas pelo aperto das curvas no lado esquerdo dos respectivos cartões. A escarpa de falha da Pena da Falsa, no polje de Alvados, fica sobranceira ao ponor da Falsa. 
até 300 metros acima do fundo aplanado do polje, fundo esse que está talhado em bisel nas camadas inclinadas do Batoniano (Fig. 2).

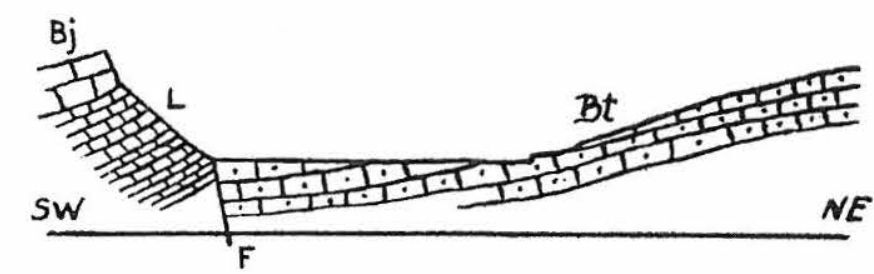

FIg. 2-Polje de Minde: corte esquemático. Escala horizontal: 1/50.000. Alturas exageradas duas vezes. $\mathrm{L}$-Liássico; $\mathrm{Bj}$-Bajociano; $\mathrm{Bt}$ - Batoniano. $\mathrm{F}-$ Falha. O fundo plano do polje desenvolve-se no sopé da grande escarpa da Costa de Minde (à esquerda).

Se considerarmos a grande deslocação acima referida e tivermos em conta, como já frisei noutro lugar, que em todo o contorno, exceptuada apenas a margem correspondente à base da Costa, as camadas mergulham para o polje, torna-se logo evidente a origem tectónica desta forma. Quer dizer, o polje de Minde não é mais do que uma cuveta tectónica afeiçoada pela erosão cársica.

E qual terá sido a importância do escavamento levado a cabo pela erosão cársica? Foi bem sublinhado por Pierre Birot que a altura relativa dos ferrolhos (verrous) não pode servir de índice, visto as camadas batonianas mergulharem para o polje, como atrás referi. Todavia, aquele morfologista calculou que «la tranche de calcaire enlevée par l'érosion fluvio-karstique est inférieure à $50 \mathrm{~m}$.», e, ao que parece, apoiou-se para fazer o cálculo na hipótese de que a vertente NE do polje coincidiria aproximadamente com o plano estratigráfico dos calcários, como o provaria, diz, a presença de materiais da cobertura siliciosa, reputada cretácica por Birot 1 . Mas este facto constituirá efectivamente prova decisiva? Apenas o seria, segundo julgo, se as areias e calhauzitos da desmantelada cobertura estivessem in situ; porém, o modo de jazida não garante tal, antes pelo contrário induz o escorregamento por solicitação da gravidade ou a translação por efeitos da diminuta escorrência. Para fazer aquele cálculo parece-me preferível assentar no facto do declive topográfico daquela vertente não se afastar muito do pendor das

1 Cf. Pierre Birot, Les Surfaces d'érosion du Portugal Central et Septentrional (in Rapport de la Commission pour la Cartographie des Surfaces d'Aplanissement - Congrès International de Géographie, Lisbonne, 1949) Louvain, 1949, pág. 96. 
camadas, que são, por sua vez, nitidamente cortadas em bisel pela superfície do fundo do polje: diríamos então que a espessura de calcário destruída pela erosão cársica, ou antes fluvio-cársica, seria da ordem dos 35-40 m., o que aliás parece ser contraprovado pelo degrau que, nalguns locais, limita, ao encontro da vertente, certas nesgas aplainadas sobranceiras ao fundo do polje e nas quais o biselamento das camadas está patente.

Cerca de Minde, uma barra cársica, alçada pouco mais de uma dúzia de metros acima do fundo actual do polje e que delimita uma depressão satélite, tem no tope um depósito de calhauzitos rolados de calcário, depósito esse ligeiramente consolidado e com espessura de 3 a 4 metros. O rolamento desses calhauzitos e a facies da formação, que também aparece esparsa na base da Costa, junto do Lombeiro, levam a admitir que num dos períodos glaciários, com maior probabilidade no decorrer do último, um lago se encastoou na depressão a favor da forte pluviosidade coeva e porque as galerias subterrâneas não escoavam toda a água recebida. Como os possíveis cursos de água superficiais contemporâneos do depósito não podeciam ter grande percurso, dada a restrita área do Maciço, obviamente não foram os agentes de tão perfeito rolamento, como aliás se contraprova fazendo a comparação com a grosseira carga sólida dos cursos temporários actuais. Terão aqueles cursos do Quaternário sido, isso sim, os agentes do transporte, mas o rolamento foi obra das águas do lago primitivo, como se poderá concluir sem esforço vendo quebrar as ondas do lago temporário que, na actualidade, se instala no polje durante o inverno.

Porém, como se terá extinguido aquele lago quaternário? Com o decorrer dos tempos a capacidade das galerias hipogeias aumentaria e, paralelamente, o total das precipitações ia diminuindo à medida que o clima se transformava; por outro lado, talvez o Maciço tenha sido soerguido ligeiramente ou haja descido o nível de base - e estas circunstâncias, quer actuassem ou não simultaneamente, contribuíram para que se esgotasse o lago quaternário e fosse desmantelada, perdendo-se nos ponors, grande parte do depósito lacustre.

Para o final desta fase da sua evolução, o polje primitivo começaria a geminar-se: na extremidade de sudeste, uma pequena bacia secundária ficaria progressivamente isolada da depressão principal: e nesta se afeiçoaria, a pouco e pouco, o fundo do polje moderno, na actualidade cerca de 15 metros abaixo da aplanação anterior.

No bordo da vertente de NE, talhado quase a pique por obra da erosão cársica post-glaciária, encontram-se dois grandes ponors - o Regatinho e o Poio, - e para o extremo NW, e mais próximo da Costa, escancara-se o Olho da Mira. Estes três ponors funcionam como emissivos após as chuvas 
continuadas da estação pluviosa ${ }^{1}$, dando origem a três ribeiros que não tardam a inundar o polje, porquanto os pequenos algares do fundo são insuficientes para drenar em igual cadência o caudal regorgitado por aqueles ponors ${ }^{2}$. A inundação do polje dura em cada ano vários meses: em regra, três a quatro, mas já tem acontecido que a inundação comece em Setembro e as águas só venham a ser totalmente esgotadas nos fins de Maio ou mesmo em princípios de Junho.

A inundação periódica do polje e sobretudo o volume das suas águas anda provavelmente na dependência, ao menos parcial, de influências estruturais complicadas pela tectónica: com efeito, porque os calcários do Batoniano mergulham para o polje, naturalmente a maioria das galerias perfuradas nesse material desce no mesmo sentido, orientada pela estratificação; porém, como essas galerias, por virtude da falha, vão de encontro aos calcários margosos do Liássico, por certo não terão nestes fácil continuação. Daí resulta, aquando dos perícdos de chuvas contínuas, que o escoamento subterrâneo seja insuficiente; tal implica um aumento do volume de águas nas condutas hipogeias e, se continua a chover, isso acarreta uma fase de saturação cársica com o consequente regorgitar dos ponors marginais e das emergências do fundo do polje - e logo a inundação.

A oscilação vertical das águas subterrâneas orça pelos 40 metros, como se deduz considerando a cota da boca do Olho da Mira e o nível a que, na estiagem, se encontram as águas na galeria desse ponor.

Dado que o polje de Minde é inundado periodicamente, a sua evolução continua; o fundo tenderá a descer paralelamente a ele mesmo e a aumentar a superfície à custa da vertente de NE, a de mais suave declive. Por outro lado, a grande escarpa da. Costa, de íngreme talude e de frescor juvenil, gozará de imunidade e será, possivelmente exagerada ainda, pois que na sua base o fundo do polje continuará a descer.

Por tudo isto, razão teve Pierre Birot quando em presença do minúsculo polje de Minde evocou o grande Popovopolje.

Polje de Alvados. - É também uma bela e vigorosa forma e igualmente na dependência de acidentes tectónicos - falhas da Costa de Alvados e da Pena Falsa (Fig. 3). Porém, se a localização do polje corresponde a uma depressão tectónica, nem por isso parece que a grande bacia tenha sido fechada

1 Em Minde, de um total anual de $1252,4 \mathrm{~mm}$. de chuva, registam-se 329,3 no Outono e 571,6 no Inverno (médias do período 1932-1944).

2 É óbvio que estes ponors funcionam também como absorventes na fase inicial do escoamento do lago temporário. 
pelas deslocações da estrutura, antes o exame no terreno sugere que a partir de uma depressão de declive contínuo - pela qual até se terá insinuado em golfo um nível de erosão - acabariam as tácticas cársicas por talhar uma bacia fechada, que por sua vez evolucionaria até ao polje. A primitiva drenagem ter-se-ia perdido quando o bloco calcário experimentou ligeiro soerguimento ou o nível de base geral baixou: consequentemente formou-se aquela bacia fechada, e, porque o nível de base cársico só lentamente acompanha a descida do nível de base geral, a toalha cársica permaneceu a pouca profundidade e, mercê das oscilações verticais impostas pela saturação, determinaria inundações periódicas. Isso acarretou o afeiçoamento pro-

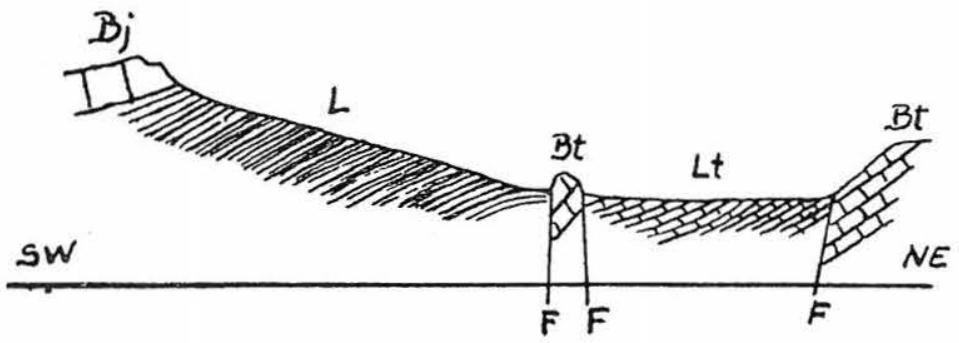

FIg. 3-Polje de Alvados: corte esquemático. Escalas horizontal e vertical: 1/25.000. $\mathrm{L}$ - Liássico; $\mathrm{Bj}$ - Bajociano; $\mathrm{Bt}$ - Batoniano; Lt - Lusitaniano superior. FF - Falhas. À esquerda ergue-se a Costa de Alvados e à direita levanta-se a rígida escarpa da Falsa. $\mathrm{O}$ fundo do polje bisela as camadas do Lusitaniano superior. Note-se a barra de calcários batonianos sobranceira ao sopé da escarpa da Costa.

gressivo do fundo e o desenvolvimento do polje, cujas condições hidrográficas, numa fase da sua evolução, ficaram testemunhadas por um manto de inundação cársica, depósito aluvial de pequenos calhaus subangulosos de calcário 1 .

Neste polje de Alvados há acidentes que faltam no de Minde: quero referir-me a alguns hums talhados numa barra de calcários do Dogger, afloramento esse que se estende no sopé do talude da Costa e, portanto, ao longo da linha de falha. A saliência de alguns tramos dessa barra explica-se facilmente: além da falha da Costa, temos de considerar uma outra, aliás já assinalada por Choffat, a qual estabelece contacto anormal entre os calcários

1 P. Birot, in Les Surfaces d'Érosion du Portugal Central et Septentrional, já cit., pág. 97, admite que este manto de inundação cársica seja provavelmente contemporâneo daquele depósito que coroa, junto de Minde, a pequena barra cársica. 
do Dogger e os do Lusitaniano superior; e assim, do lado do SW estamos em presença de uma escarpa de linha de falha invertida (erosional fault-scarp), posta em saliência a rocha dura em detrimento dos materiais mais brandos do talude liássico da Costa, e, por sua vez, do lado NE, temos apenas uma escarpa de falhas, ainda que exagerada pela erosão diferencial. Aos tramos salientes desta barra poder-se-á chamar - e, quanto se me afigura, legitimamente - hums estruturais.

$\mathrm{Na}$ grande escarpa que domina o polje - a Costa - temos um decalque do que se passa na Costa de Minde: um talude liássico, coroado por uma cornija de calcários bajocianos. Contudo o recuo da escarpa é aqui muito mais acentuado do que em Minde. Para explicar tall disparidade poderá invocar-se a diferença de idade dos acidentes - na opinião de Birot, a falha de Alvados é mais antiga -; porém, aquele maior recuo pode ser apenas consequência de serem os materiais da escarpa bem mais brandos em Alvados, como efectivamente são.

Segundo aquele morfologista a espessura dos calcários digeridos no polje alcança 100-150 metros; muito embora não se me tenham ainda deparado factos concretos para apoiar qualquer estimativa, reputo exageradas aquelas cifras e quer-me parecer ter sido o cálculo de Birot perturbado por errada interpretação da escarpa da Pena Falsa.

Retomando o fio da descrição, sublinharei que, tal como no polje de Minde, também o de Alvados é formado por duas secções: no extremo SE, talhada nos calcários duros e compactos, de fundo rochoso e mal aplainado, está uma pequena depressão cársica, cuja evolução continua; para NW, estende-se uma plataforma de erosão bem nivelada e que bisela camadas do Lusitaniano superior, francamente inclinadas. Essa plataforma, que alastra pela maior parte da superfície do polje e sobre a qual assenta o depósito aluvial acima referido, foi já conquistada pela erosão normal. Como terá sucedido tal?

A regressão de Würm, que em frente da costa portuguesa determinou a descida do nível do mar até -100 metros, deve ter repercutido, atenuando-a, na periodicidade das inundações do polje, porquanto a brusca descida do nível de base dos rios próximos acarretou implicitamente um exacerbamento na marcha das águas para a profundidade; daí um aumento da capacidade das condutas subterrâneas e, consequentemente, a descida da zona húmida. Somando-se a estas circunstâncias a progressiva diminuição da pluviosidade a partir do Würm é provável que, decde logo, e apesar mesmo das crises epiglaciárias, as inundações do polje tenham diminuído de volume e perdido a periodicidade anual. 
A descida do nível de base suscitou ainda uma vaga de erosão regressiva que, desde o Lena, subindo o vale do Alcaide, abriu a forma cársica, facilitada que foi a tarefa das exsurgências do curso subterrâneo, as quais, a favor de forte pluviosidade, jogavam decisivamente a montante. Aliás o processo está ainda bem patente na série de exsurgências escalonadas no vale desse afluente do Lena: a situada mais a jusante fica próxima do lugarejo chamado Rio Alcaide e para montante dispõe-se um rosário de outras temporárias. Todo o sistema, que é tributário do Lena, tem as cabeceiras no Buraco da Velha, exsurgência ocasional na actualidade, e na Falsa, situada no bordo nordeste do polje e que apenas jorra na estação pluviosa, como tributária do Lena.

A natureza do material que constitui a formação aluvial e a frescura do depósito permitem afirmar que nos últimos tempos do Pleistoceno ainda o polje teria inundações; logo, só posteriormente a erosão regressiva terá incluído a grande forma cársica na bacia do Lena. E assim o polje de Alvados, conquistado pela erosão normal, lembra os poljes abertos da região do Narenta, referidos por Cvijič.

Estes dois poljes - o de Minde e o de Alvados - cujos fundos se desenvolvem, respectivamente, a 180-190 metros e 225-230 metros, são duas belas formas de evidentes semelhanças na arquitectura mas de evolução bem diversa. Modelos minúsculos e de relativa simplicidade, poderá dizer-se deles que constituem excelente material pedagógico.

Junho, 1951

FERNANDES MARTINS 